\title{
Stimulus Contrast Affects Spatial Integration in the Lateral Geniculate Nucleus of Macaque Monkeys
}

\author{
Darlene R. Archer, ${ }^{1,2,3}{ }^{\circledR}$ Henry J. Alitto, ${ }^{1}$ and ${ }^{\circledR}$ W. Martin Usrey ${ }^{1}$ \\ ${ }^{1}$ Center for Neuroscience, University of California, Davis, Davis, California 95616, ${ }^{2}$ SUNY College of Optometry, New York, New York 10036, and \\ ${ }^{3}$ Center for Neural Science, New York University, New York, New York 10003
}

Gain-control mechanisms adjust neuronal responses to accommodate the wide range of stimulus conditions in the natural environment. Contrast gain control and extraclassical surround suppression are two manifestations of gain control that govern the responses of neurons in the early visual system. Understanding how these two forms of gain control interact has important implications for the detection and discrimination of stimuli across a range of contrast conditions. Here, we report that stimulus contrast affects spatial integration in the lateral geniculate nucleus of alert macaque monkeys (male and female), whereby neurons exhibit a reduction in the strength of extraclassical surround suppression and an expansion in the preferred stimulus size with low-contrast stimuli compared with high-contrast stimuli. Effects were greater for magnocellular neurons than for parvocellular neurons, indicating stream-specific interactions between stimulus contrast and stimulus size. Within the magnocellular pathway, contrast-dependent effects were comparable for ON-center and OFF-center neurons, despite $\mathrm{ON}$ neurons having larger receptive fields, less pronounced surround suppression, and more pronounced contrast gain control than OFF neurons. Together, these findings suggest that the parallel streams delivering visual information from retina to primary visual cortex, serve not only to broaden the range of signals delivered to cortex, but also to provide a substrate for differential interactions between stimulus contrast and stimulus size that may serve to improve stimulus detection and stimulus discrimination under pathway-specific lower and higher contrast conditions, respectively.

Key words: Key words:extraclassical; gain control; LGN; parallel pathways; receptive field; suppression

\section{Significance Statement}

Stimulus contrast is a salient feature of visual scenes. Here we examine the influence of stimulus contrast on spatial integration in the lateral geniculate nucleus (LGN). Our results demonstrate that increases in contrast generally increase extraclassical suppression and decrease the size of optimal stimuli, indicating a reduction in the extent of visual space from which LGN neurons integrate signals. Differences between magnocellular and parvocellular neurons are noteworthy and further demonstrate that the feedforward parallel pathways to cortex increase the range of information conveyed for downstream cortical processing, a range broadened by diversity in the $\mathrm{ON}$ and OFF pathways. These results have important implications for more complex visual processing that underly the detection and discrimination of stimuli under varying natural conditions.

\section{Introduction}

Visual features in the natural environment vary greatly in luminance contrast and size. To encode these variations efficiently, visual neurons can adjust their responses according to the statistics of the visual scene. Gain-control mechanisms play a prominent role in this process and are evident at every stage in the

Received Nov. 19, 2020; revised May 30, 2021; accepted June 2, 2021.

Author contributions: W.M.U. designed research; D.R.A. and H.J.A. performed research; D.R.A. analyzed data; D.R.A. and W.M.U. wrote the paper.

This work was supported by National Institutes of Health Grants EY-013588, MH-082174, and P30-EY12576. We thank K.E. Neverkovec, D.J. Sperka, J.S. Johnson, and R. Oates for expert technical assistance; and

Dr. Jose-Manuel Alonso for helpful discussions and comments on the manuscript.

Correspondence should be addressed to W. Martin Usrey at wmusrey@ucdavis.edu.

https://doi.org/10.1523/JNEUROSCI.2946-20.2021

Copyright $\odot 2021$ the authors visual system, often regulating neuronal responses to adjust the sensitivity for stimuli and/or the operating range for processing sensory signals.

Two manifestations of gain control are contrast gain control and extraclassical suppression. Contrast gain control is the phenomenon whereby visual responses are amplified at low contrasts and compressed at high contrasts (Shapley and Victor, 1978; Enroth-Cugell and Freeman, 1987; Victor, 1987; Benardete et al., 1992). Models of retinal mechanisms for contrast gain control often include the combining of linear and nonlinear subunits that dynamically adjust their gain to different contrasts (Shapley and Victor, 1978; Enroth-Cugell and Freeman, 1987; Victor, 1987; Benardete et al., 1992; Chander and Chichilnisky, 2001; Kim and Rieke, 2001). The combination of functional subunits is thought to span a region of visual space that is as large as or larger than the classical receptive field (RF) of a neuron, thereby 
potentially contributing to a second form of gain control known as extraclassical suppression (Bonin et al., 2005), a phenomenon in which responses to stimuli within the classical receptive field of a neuron are suppressed by stimuli within the extraclassical surround (Allman et al., 1985; Sillito et al., 1993; Jones et al., 2000; Solomon et al., 2002, 2006; Alitto and Usrey, 2008; Fisher et al., 2017). As these two manifestations of gain control may include shared (Bonin et al., 2005) and/or distinct retinal mechanisms (Kim and Rieke, 2001; Rieke, 2001; Zaghloul et al., 2007; Jarsky et al., 2011; Weick and Demb, 2011; Greschner et al., 2016), as well as extraretinal mechanisms affecting lateral geniculate nucleus (LGN) responses (Sillito and Jones, 2002; Rathbun et al., 2016; Fisher et al., 2017), it is important to know whether and how they interact, as these interactions could have pronounced effects on visual processing.

The effect of stimulus contrast on extraclassical suppression could be distinct for neurons in the parallel retino-geniculo-cortical pathways. In primates, two major pathways from retina to cortex are the magnocellular and parvocellular pathways, which each include ON-center and OFF-center streams. Compared with neurons in the parvocellular pathway, neurons in the magnocellular pathway have larger receptive fields, shorter visual response latencies, and more transient responses to visual stimuli (for review, see Schiller and Logothetis, 1990; Merigan and Maunsell, 1993; Usrey and Alitto, 2015). Magnocellular neurons also exhibit greater contrast gain control and stronger extraclassical suppression than parvocellular neurons (Solomon et al., 2002; Alitto and Usrey, 2008). Although contrast gain control and extraclassical suppression are evident in the retinal ganglion cells (RGCs) that innervate neurons in the LGN of the thalamus (Solomon et al., 2006; Alitto and Usrey, 2008), reports indicate that these forms of gain control are more pronounced in the LGN compared with the retina (Rathbun et al., 2016; Fisher et al., 2017; but see Alitto and Usrey, 2008). Thus, extraretinal mechanisms may influence interactions between stimulus contrast and stimulus size along the retino-geniculocortical pathway, presumably to enhance visual processing in the cortex and benefit visual behavior.

The goal of this study was to assess the influence of stimulus contrast on extraclassical suppression and optimal stimulus size in LGN neurons of alert macaque monkeys to avoid potential confounds associated with anesthesia effects on visual responses (Alitto et al., 2011; Vaiceliunaite et al., 2013) and to determine whether contrast-dependent changes in spatial integration differ for LGN neurons relaying signals in the parallel visual pathways. Across cell types, the strength of extraclassical suppression typically increased as stimulus contrast increased, and increased suppression was accompanied with shifts in the peak response to smaller optimal-size stimuli, indicating a reduction in the spatial extent over which LGN neurons integrate visual signals. Effects were most pronounced for magnocellular neurons compared with parvocellular neurons, and differences between ONcenter and OFF-center magnocellular neurons in spatial integration and contrast gain control were noteworthy. Together, these findings demonstrate that stream-specific interactions between stimulus contrast and stimulus size broaden the range of signals delivered to cortex. Moreover, the inverse relationship between contrast and spatial integration and the diversity across cell types should have functional consequences for stimulus detection and discrimination during natural vision.

\section{Materials and Methods}

Two adult rhesus monkeys (Macacca mulatta;one female and one male) were used for electrophysiological recordings in this study. All experimental procedures conformed to National Institutes of Health and United States Department of Agriculture guidelines and were approved by the Institutional Animal Care and Use Committee at the University of California, Davis. Under full surgical anesthesia, the monkeys received a cranial implant containing a head post for head stabilization. Animals were then trained to fixate on a target dot for fluid reward while eye position was monitored with an infrared eye-tracking system (model ASL-6, Applied Science Laboratories) with a sampling rate of $1000 \mathrm{~Hz}$. Following fixation training, a stainless steel recording cylinder (Crist Instruments) centered over the LGN (7 $\mathrm{mm}$ anterior to the interaural axis and $11 \mathrm{~mm}$ lateral from the midline) was added to the implant.

\section{Electrophysiological recordings and visual stimuli}

Single-unit recordings from LGN neurons were made using platinumin-glass electrodes (1-2 M $\Omega$; Alpha Omega). Using a microdrive (40 $\mathrm{mm}$ electrode travel; Thomas Motorized Electrode Manipulator, Thomas RECORDING) mounted on the recording chamber, electrodes were advanced through a stainless steel guide tube to the LGN, $\sim 23 \mathrm{~mm}$ below the cortex. Continuous voltage signals containing the action potentials of single units were amplified (A-M Systems), filtered (0.1$5 \mathrm{kHz}$ ), and recorded using a Micro1401 data acquisition system $(28 \mathrm{kHz})$ and Spike2 software (both from CED). Unit isolation was confirmed offline using waveform analysis and the presence of a refractory period (Bishop and Evans, 1956), as indicated in the autocorrelograms.

Visual stimuli were generated with a ViSaGe (Cambridge Research Systems) and presented on a gamma-corrected CRT monitor (Sony or Mitsubishi) positioned in front of the animal (at 65 and $80 \mathrm{~cm}$ for monkeys 1 and 2, respectively); the display had a resolution of $1024 \times 768$, a refresh rate of $140 \mathrm{or} 120 \mathrm{~Hz}$, and a mean luminance of $38 \mathrm{~cd} / \mathrm{m}^{2}$. At the beginning of each recording session, eye position was calibrated by having the animal fixate target points displayed at known eccentricities. Receptive field locations of recorded neurons were determined manually using small spots and/or grating patches. Visual stimuli were centered on the receptive fields of recorded cells. Importantly, centering was confirmed and maintained throughout data collection. To minimize errors arising from eye movements, trials were aborted if eye position deviated by $>0.35^{\circ}$, and data from trials with broken fixation were discarded.

Visual stimuli appeared after $200 \mathrm{~ms}$ of fixation and were presented for $1.5 \mathrm{~s}$ during which the animal was required to maintain fixation of a $0.2^{\circ}$ target dot centered within a $0.5^{\circ}$ radius window for a fluid reward. Individual trials were presented in three to seven blocks of randomly interleaved stimulus diameters such that each stimulus diameter was presented once during each block. A mean gray interstimulus interval of $1.5 \mathrm{~s}$ was interleaved between each stimulus presentation during which animals could move their eyes freely.

We measured responses evoked by drifting sinusoidal gratings (temporal frequency, 4 or $5 \mathrm{~Hz}$ ) to characterize receptive field response properties. We presented nine spatial frequencies (100\% contrast) in octave steps (range, $0.2-8 \mathrm{c} /{ }^{\circ}$ ) to characterize the spatial frequency tuning function. From the online spatial frequency response functions, we obtained the frequency that gave the peak response (preferred spatial frequency) and used this spatial frequency for all subsequent stimulus gratings. To measure responses as a function of stimulus size, we presented gratings at nine stimulus diameters (range, $0.2^{\circ}-5^{\circ}$ ). Contrast response functions were made based on responses to nine luminance contrasts (range, 1$100 \%$ in logarithmic steps). To examine the effect of contrast on extraclassical suppression and optimal stimulus size, we measured size-tuning responses at high and low contrasts.

\section{Data analysis}

LGN responses were analyzed using the first harmonic (F1) of spiking responses modulated at the temporal frequency of the drifting sinusoidal grating. To find the model parameters that best accounted for the measured responses, a constrained nonlinear least-squares optimization routine, implemented in MATLAB (fmincon), was used when fitting response functions. 
Spatial frequency response functions. We fit responses to stimuli that varied in spatial frequency with a frequency domain difference of Gaussians (DoG) function (Enroth-Cugell and Robson, 1966) with the following form:

$$
R\left(w_{x}\right)=K\left(\left[\exp -\left(w_{(x)} / f_{c}\right)^{2}\right]-K_{s}\left[\exp -\left(w_{x} / f_{s}\right)^{2}\right]\right),
$$

where $\omega_{x}$ is the spatial frequency, $K$ is an overall scaling factor, $f_{c}$ is the characteristic spatial frequency of the center Gaussian (frequency at which the response falls to $1 / e$ of its maximum), $K_{s}$ is the integrated weight of the surround relative to the center, and $f_{s}$ is the characteristic frequency of the surround Gaussian.

Contrast response functions. Contrast response functions were made for a subset of neurons $(n=54)$. We fit contrast responses with a hyperbolic ratio function (Naka and Rushton, 1966; Albrecht and Hamilton, 1982):

$$
R(C)=k * C^{n} /\left(C^{n}+C_{50}^{n}\right)+b
$$

where $C$ denotes the luminance contrast of the stimulus, $k$ represents the maximum response, the exponent $n$ reflects the linearity of the response function, $C_{50}$ refers to the semisaturation contrast, and $b$ is the baseline response of the cell. The hyperbolic ratio fits were very good in most cases (mean $R^{2}=0.93$ ).

From the hyperbolic ratio fits, we estimated that the contrast required to evoke half of the maximum response $\left(\mathrm{C}_{50}\right)$, a value that reflects the slope of the contrast response function, and we used this measure to quantify the contrast gain for a given cell.

To examine extraclassical suppression and optimal stimulus size across neurons, we selected contrast levels above and below the $C_{50}$ value of each cell in the linear range of the contrast response function (typically, the $\mathrm{C}_{25}$ and $\mathrm{C}_{75}$ values, assessed online) to generate area summation response functions.

Size-tuning response functions. We fit responses to stimulus diameter with a spatial domain DoG function (Sceniak et al., 1999) with the following form:

$$
R(d)=K_{c} \int_{(-d / 2)}^{(d / 2)} \exp \left(-\left[2 y / \sigma_{c}\right]^{2}\right)-K_{s} \int_{(-d / 2)}^{(d / 2)} \exp \left(-\left[2 y / \sigma_{s}\right]^{2}\right),
$$

where $d$ is the stimulus diameter in degrees, $K_{c}$ and $\sigma_{c}$ specify the amplitude and width of the center Gaussian, and $K_{s}$ and $\sigma_{s}$ specify the amplitude and width of the surround Gaussian. The only constraint imposed when fitting the data was $\sigma_{c}<\sigma_{s}$.

From the DoG fits, we obtained the peak response and asymptotic response to estimate the degree in which the extraclassical surround modulates the response of the classical center (DeAngelis et al., 1994). Using these measures, we calculated the suppression index (SI), defined as follows:

$$
\mathrm{SI}=\left(R_{\text {peak }}-R_{\text {asym }}\right) /\left(R_{\text {peak }}+R_{\text {asym }}\right),
$$

where $R_{\text {peak }}$ reflects the maximum response across all stimulus diameters, and $R_{\text {asym }}$ reflects the asymptotic response to the largest stimulus diameter. SI values are bound between 0 and 1 , with values near 0 representing weak suppression, and larger values representing strong suppression. We obtained the stimulus diameter eliciting the peak response to estimate the optimal stimulus size, a value that approximates the size of the classical receptive field.

Changes in the optimal stimulus size as a function of contrast were quantified using a bounded index, as follows:

$$
\begin{aligned}
& \left(\text { Opt.size }_{\text {low contrast }}-\right.\text { Opt.size } \\
& \text { high contrast } \\
& \left.- \text { Opt.size }_{\text {high contrast }}\right) \text { Opt.size }
\end{aligned}
$$

\section{Cell classification}

We classified cells as magnocellular or parvocellular using clustering analysis in MATLAB. Hierarchical clustering performed a weighted linkage algorithm based on the contrast evoking $\mathrm{C}_{50}$ and the slope of the contrast response function for lower contrasts (1.8\% to 17.8\%). Consistent with our previous findings (Alitto and Usrey, 2008), this method generated clusters where cells with a $\mathrm{C}_{50}$ value $<35 \%$ were classified as magnocellular $(n=35)$ and cells with a $C_{50}$ value $>35 \%$ were classified as parvocellular $(n=19)$. Because recording sites were not confirmed with lesions and histology (not a feasible practice for data collected from behaving animals), we consider the classification of cell types as putative magnocellular and putative parvocellular.

Cells were further classified as ON-center or OFF-center based on their response to the phase of the sinusoidal grating. Cells excited by the bright phase of the stimulus were classified as ON cells, and cells excited by the dark phase were classified as OFF cells. Given that the smaller number of parvocellular cells $(n=19$, total) did not allow for significant statistical analysis, we restricted the ON-OFF analysis to our sample of magnocellular cells, as we had a sufficient sample size of both cell types ( $n=19$ and $n=16$ for OFF and ON cells, respectively).

\section{Statistics}

All analyses were performed using built-in MATLAB functions and custom scripts. The nonparametric Wilcoxon signed-rank test (MATLAB function signrank) was used to evaluate the effect of stimulus contrast within a single cell and to determine $p$ values for all pairwise statistical tests. The nonparametric Wilcoxon rank sum test (MATLAB function: ranksum) was used to compare measures of SI, optimal size, $\mathrm{C}_{50}$, response gain, and contrast-dependent changes between cell-type groups, and to determine $p$ values for statistical tests.

A Spearman (rank) correlation coefficient (MATLAB function: corr) was calculated to quantify the relationship between measures of interest and determine significance. From correlations, we calculated a Spearman (rank) partial correlation coefficient (MATLAB function: partialcorr) as follows:

$$
r_{x y . z=\left(r_{x y}-r_{x z} r_{y z}\right)} / \sqrt{ }\left(1-r_{\mathrm{xz}}^{2}\right)\left(1-r_{\mathrm{yz}}^{2}\right),
$$

to confirm the relationship between two measures of interest $(x, y)$ while controlling for the effect of a third measure $(z)$ and to determine significance.

For all comparisons, the mean and the SEM are reported, and the number of neurons in each group is presented as values for $n$. Probability values are provided for all statistical comparisons, and probability values $<0.001$ are described as $p<0.001$. All statistical methods were two sided.

\section{Results}

Stimulus contrast and stimulus size are known to govern the responses of neurons in the LGN and, therefore, the visual signals relayed to cortex. We made single-unit recordings from neurons $(n=75)$ in the LGN of two awake, fixating macaque monkeys to determine how these stimulus features interact. For each neuron, we measured responses to drifting sinusoidal gratings (optimal spatial frequency; temporal frequency, 4 or $5 \mathrm{~Hz}$ ), that were centered over the receptive field and varied in contrast and size (i.e., diameter of the grating patch).

Figure 1, $A$ and $B$, shows the spiking activity and firing rates of an example LGN neuron for stimuli of different contrasts and sizes. The periodic spiking activity in the raster plots (Fig. $1 A$ ) reflects the phase and temporal frequency of the drifting sinusoidal grating. As expected, the spiking activity of this neuron increases as stimulus contrast increases $(5 \%, 8 \%$, and $18 \%$ contrast). Activity levels of this neuron are also affected by stimulus size, as illustrated with each of the response curves in Figure $1 B$. Beginning with the smallest size stimuli, the initial increase in the response function largely reflects the extent to which the stimulus fills the classical receptive field of the neuron. The peak 
A

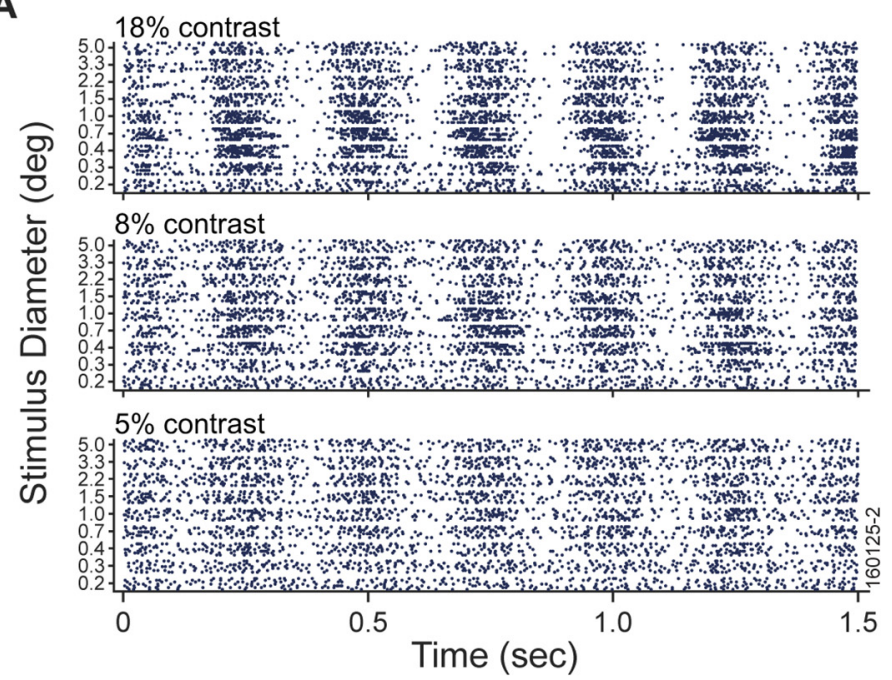

B

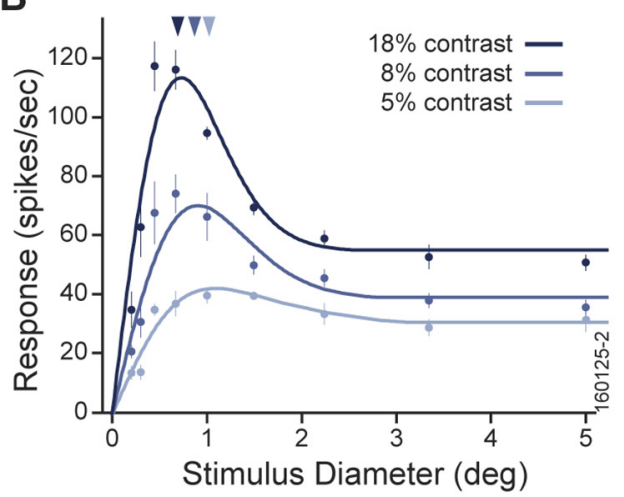

D

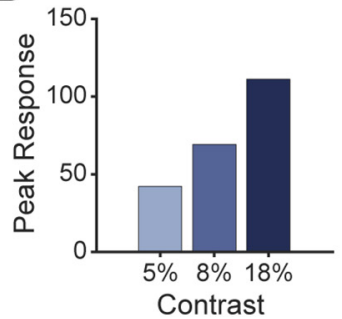

$\mathrm{E}$

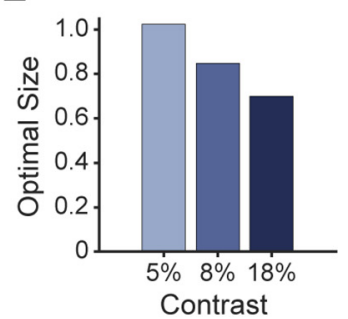

C

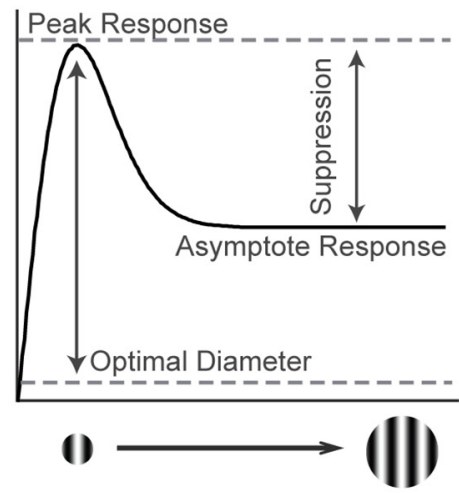

$\mathbf{F}$

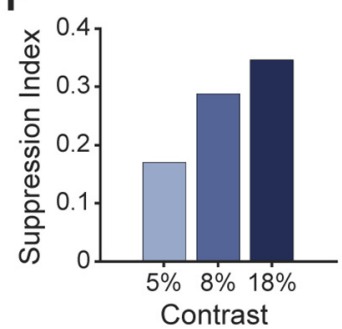

Figure 1. Stimulus contrast and size affect LGN responses. $\boldsymbol{A}$, Raster plot of responses (tick marks) from an example LGN (magnocellular) neuron to drifting sinusoidal gratings varying in stimulus diameter (rows) and stimulus contrast (panels) across time. $\boldsymbol{B}$, Area summation responses for the same neuron at different stimulus contrasts fit with a difference of Gaussian function indicated with solid lines. Closed circles and error bars represent the mean \pm SEM. C, Illustration of area summation response curve and parameters of interest. $\boldsymbol{D}-\boldsymbol{F}$, Peak response, optimal size, and suppression indexmeasured at three levels of contrast for the example LGN neuron.

response (arrowheads) corresponds to the optimal stimulus size, a value that approximates the size of the classical receptive field and marks the border for response reinforcement (i.e., spatial integration; see Materials and Methods). Consistent with the view that the extraclassical receptive field overlaps and extends beyond the classical receptive field, stimulus sizes larger than the optimal size suppress the firing rate of the neuron as suppression increases at a faster pace than excitation until a plateau response is reached, at which point the stimulus extends beyond the size of the extraclassical surround. This example neuron exhibits substantial extraclassical suppression for higher contrast stimuli (18\% contrast) and less suppression for lower contrast stimuli $(5 \%$ contrast). Additionally, the rightward shift in the size-tuning response curves with lower contrasts reveals an inverse relationship between stimulus contrast and preferred stimulus size.

To examine the effect of contrast on extraclassical surround suppression across the sample of LGN neurons, we calculated a bounded SI (the difference between the peak response and asymptote response divided by the sum of these responses; Fig. 1C; see Materials and Methods). For the example LGN neuron in Figure 1 , increases in stimulus contrast increased the peak response of the cell (Fig. 1D), decreased the optimal size for peak response (Fig. 1E), and increased the suppression index (Fig. $1 F)$.

Similar to the example neuron in Figure 1, contrast had a prounounced influence on extraclassical suppression (Fig. 2A) and size tuning (Fig. 2B) across our sample of LGN neurons $(n=75)$. Using a wide range of stimulus contrasts (mean high contrast used $=54.9 \pm 3.9 \%$; mean low contrast used $=17.7 \pm 1.6 \%$ ), the SI was significantly increased as the stimulus contrast was increased (Wilcoxon signed-rank test; $p<0.001$ ). Overall, suppression indices were $\sim 44 \%$ greater for stimuli at higher contrasts (mean SI, $0.23 \pm 0.01)$ compared with lower contrasts (mean SI, $0.16 \pm 0.01 ; p<0.001$, Wilcoxon rank sum test). Stimulus contrast also affected the size of the preferred stimulus. Across LGN neurons, optimal sizes were $\sim 20 \%$ larger for stimuli at lower contrasts (mean optimal size, $0.96^{\circ} \pm$ $0.04^{\circ}$ ) compared with higher contrasts (mean optimal size, $0.80^{\circ} \pm 0.04^{\circ}$; $p=0.004$, Wilcoxon rank sum test). Together, the increase in optimal stimulus size and the reduction in extraclassical suppression are consistent with results from cortical neurons showing an increase in the extent of spatial integration at low contrast compared with high contrast (Levitt and Lund, 1997; Kapadia et al., 1999; Sceniak et al., 1999; Shushruth et al., 2009); however, not all cells displayed similar effects from contrast, and we therefore examined the influence of stimulus contrast on a subset of LGN neurons in our sample with clear cell-class identity (below).

\section{Magnocellular and parvocellular responses to stimulus contrast}

Magnocellular and parvocellular LGN neurons have distinct response profiles for stimuli that vary in stimulus contrast (for review, see Schiller and Logothetis, 1990; Merigan and Maunsell, 1993). Figure 3 shows the contrast response functions of an example parvocellular and magnocellular neuron. As is typical for these cell types, the magnocellular neuron is more sensitive to low-contrast stimuli compared with the parvocellular neuron. 

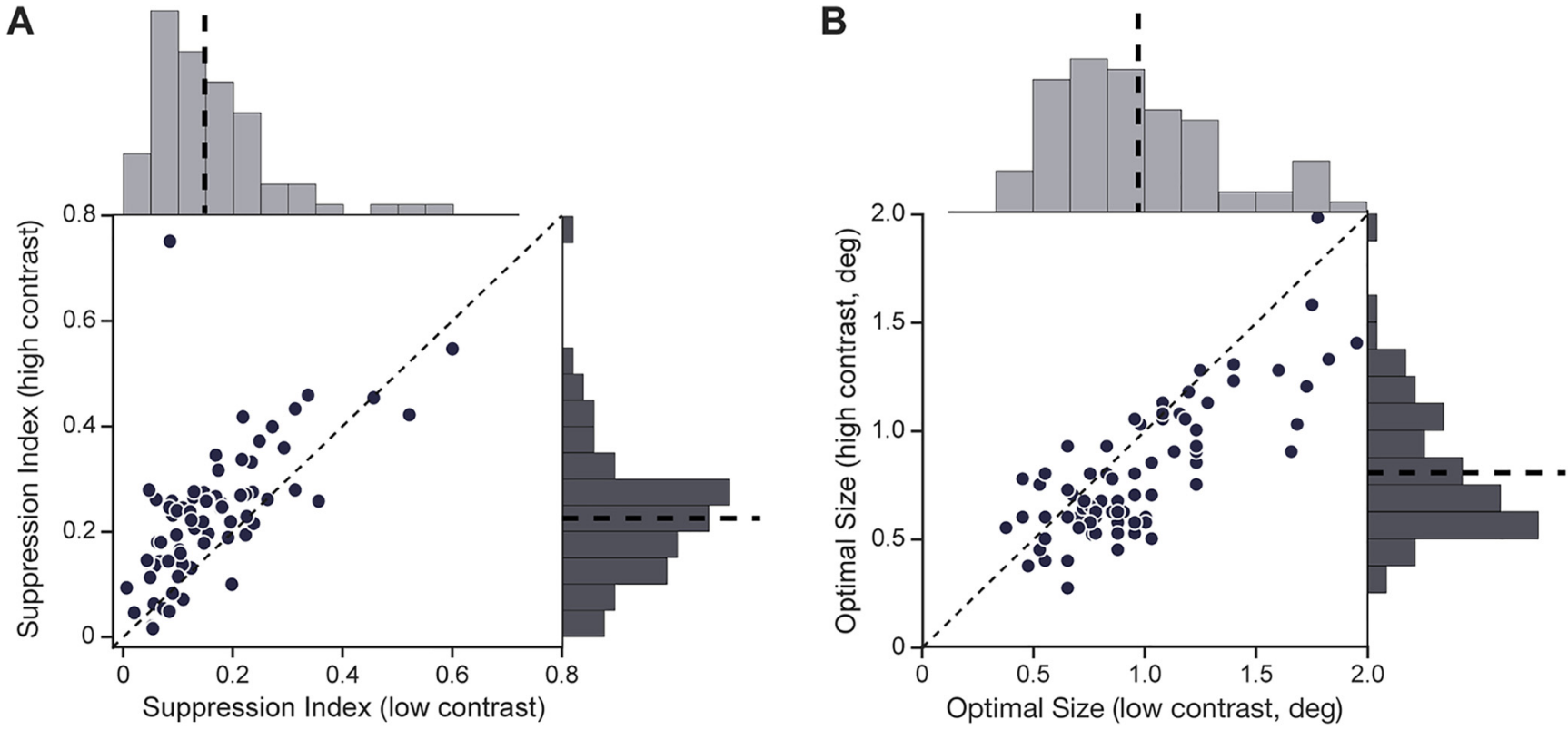

Figure 2. Contrast dependence of spatial integration. $A$, Scatter plot of the suppression index at high-contrast and low-contrast conditions across our sample of $L G N$ neurons $(n=75)$. The distributions are histograms of suppression index values at high contrast and low contrast, the dashed lines indicate the mean for each contrast condition. $\boldsymbol{B}$, Scatter plot of the optimal size at high-contrast and low-contrast conditions across our sample of $\mathrm{LGN}$ neurons $(n=75)$. The distributions are histograms of optimal size values at high contrast and low contrast, the dashed lines indicate the mean for each contrast condition.
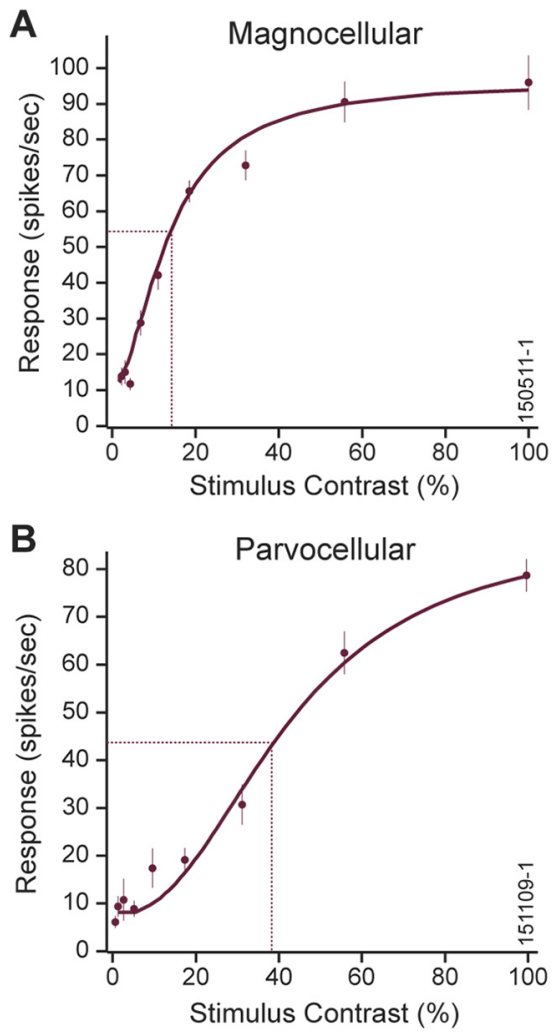

Figure 3. Variations in how cells respond to changes in stimulus contrast. $A$,Contrast response function for an example LGN magnocellular neuron. $\boldsymbol{B}$, Contrast response function for an example LGN parvocellular neuron. Solid lines indicate the hyperbolic ratio function fit. Closed circles and error bars indicate the mean $\pm \mathrm{SEM}$. Dotted lines indicate the contrast to evoke a $\mathrm{C}_{50}$.

For the example magnocellular neuron (Fig. $3 A$ ), response rates increase relatively linearly over a contrast range of $\sim 2-25 \%$, at which point, responses begin to saturate. The contrast required to evoke half of the $\mathrm{C}_{50}$ value of the cell is $\sim 13 \%$. For the parvocellular neuron (Fig. $3 B$ ), response rates are substantially more linear over a broader range, from $\sim 15 \%$ to $80 \%$ contrast, and the $\mathrm{C}_{50}$ value is higher, $\sim 38 \%$. In the following sections, we examine the influence of stimulus contrast on extraclassical suppression and optimal size for a subset of neurons that were identified as magnocellular $(n=35)$ or parvocellular $(n=19$; see Materials and Methods). For each neuron, we determined the contrast levels within the linear range of the responses, and we selected contrasts near the high and low ends of this range (above and below the $\mathrm{C}_{50}$, assessed online) for subsequent evaluation of contrast-dependent changes between cell types.

\section{Contrast-dependent effects on suppression and optimal size are greater in magnocellular neurons than in parvocellular neurons}

As an initial analysis, we compared the strength of extraclassical suppression between magnocellular and parvocellular neurons. Magnocellular neurons displayed significantly stronger extraclassical suppression than parvocellular neurons when shown higher contrast stimuli (Fig. $4 A ; p=0.003$, Wilcoxon rank sum test). A similar relationship was also evident with lower-contrast stimuli; however, the difference between magnocellular and parvocellular neurons did not reach significance (Fig. $4 A ; p=0.09$, Wilcoxon rank sum test). Thus, cell-type differences in extraclassical suppression were contingent on contrast.

Among magnocellular neurons, suppression indices were $\sim 60 \%$ greater for stimuli at higher contrast than at lower contrast (Fig. $4 B$; mean SI: high contrast $=0.29 \pm 0.02$; low contrast $=$ $0.18 \pm 0.01 ; p<0.001$, Wilcoxon rank sum test; mean high contrast used $=27.0 \pm 2.7 \%$; mean effective contrast (i.e., percentage of maximum response) $=71.3 \pm 2.2 \%$ ); mean low contrast used $=9.0 \pm$ $0.7 \%$; mean effective contrast $=37.4 \pm 2.3 \%)$. This effect was typical of magnocellular neurons, with $91 \%$ of magnocellular neurons (32 of 35) showing an increase in surround suppression at higher contrasts compared with lower contrasts $(p<0.001$, Wilcoxon signed rank test). For the parvocellular neurons in our sample, we did not 
A

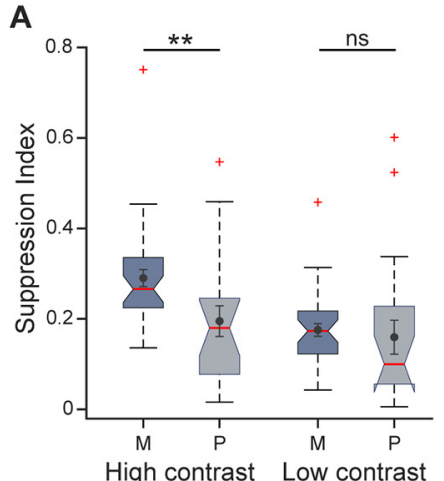

E

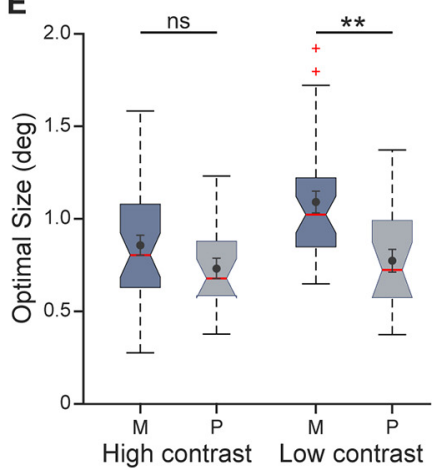

B

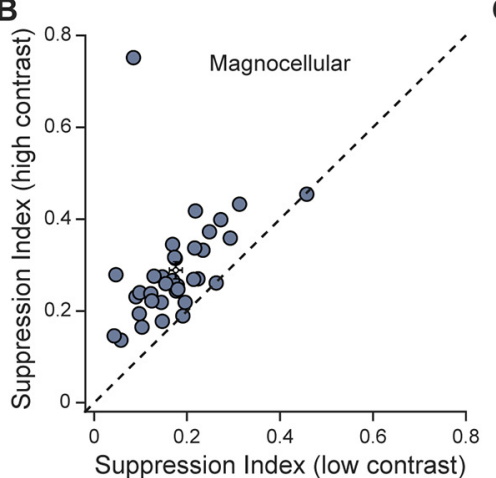

$\mathbf{F}$

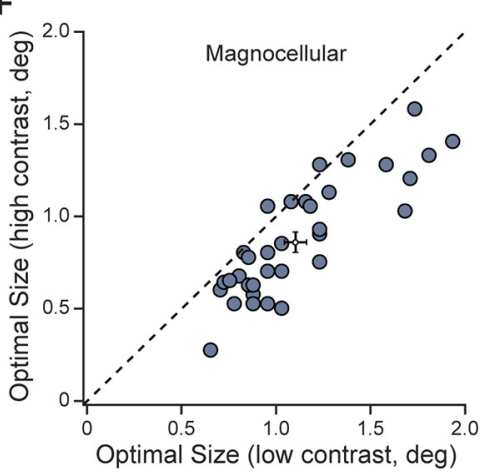

C

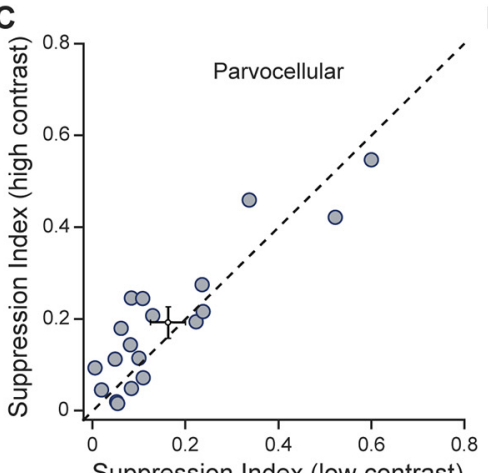

G

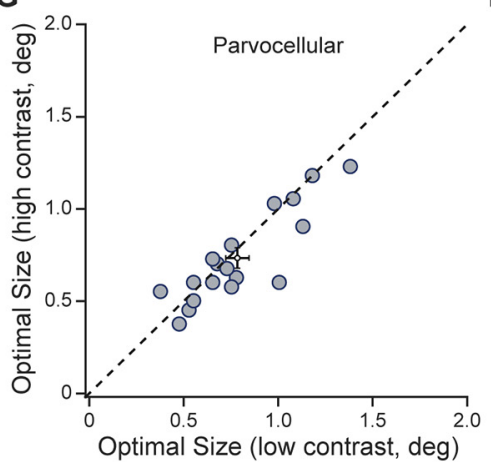

D

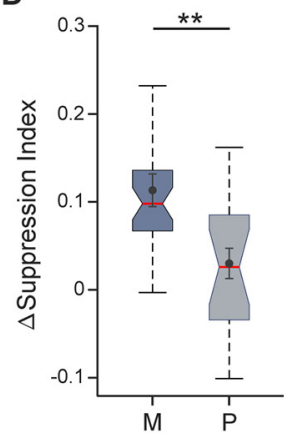

$\mathrm{H}$

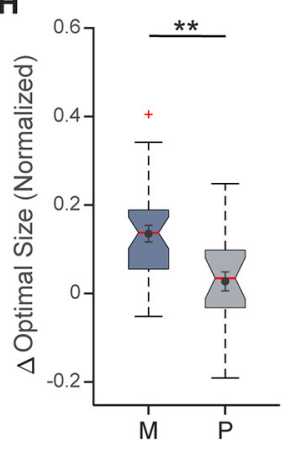

Figure 4. Influence of contrast on suppression and size preferences of cells in the magnocellular and parvocellular pathways. $A$, Box plots showing the distribution of suppression index values under high-contrast and low-contrast conditions for magnocellular cells $(n=35)$ and parvocellular cells $(n=19)$. The red horizontal lines within each box represent the median values, and the notches indicate the $95 \%$ confidence interval for the median. Edges of the boxes represent the 25th and 75th percentiles, and the whisker bars extending beyond the box correspond to the data range, excluding outlying data points that are shown individually (red crosses). Superimposed circles and error bars indicate the mean \pm SEM. $\boldsymbol{B}$, Scatter plot of the suppression index at high-contrast and low-contrast conditions for magnocellular cells, indicating an increase in suppression strength at high contrast as shown by the data above the unity line. C, Scatter plot of the suppression index at high and low contrast conditions for parvocellular cells. D, Distributions of contrast-dependent changes in the suppression index for magnocellular cells and parvocellular cells. $\boldsymbol{E}$, Distributions of optimal size values under high-contrast and low-contrast conditions for magnocellular cells $(n=35)$ and parvocellular cells $(n=19)$. $\boldsymbol{F}$, Scatter plot of the optimal stimulus size at high-contrast and low-contrast conditions for magnocellular cells, indicating an increase in the optimal size at low contrast as shown by the data below the unity line. $\mathbf{G}$, Scatter plot of the optimal size at high-contrast and low-contrast conditions for parvocellular cells. $\boldsymbol{H}$, Distributions of contrast-dependent changes in optimal size (bounded index; see Materials and Methods) for magnocellular cells and parvocellular cells.

see a significant influence of stimulus contrast on extraclassical suppression (Fig. $4 C$; mean SI: high contrast $=0.19 \pm 0.02$; low contrast $=0.16 \pm 0.04 ; p=0.13$, Wilcoxon signed-rank test; mean high contrast used $=56.5 \pm 3.6 \%$; mean effective contrast $=60.5 \pm$ $4.3 \%$; mean low contrast used $=30.8 \pm 2.9 \%$; mean effective contrast $=17.1 \pm 3.5 \%$ ); however, we cannot rule out the possibility that a significant, albeit small, difference might have been detected with a larger sample size. Nevertheless, compared with parvocellular neurons (mean change in $\mathrm{SI}=0.03 \pm 0.02$ ), magnocellular neurons (mean change in $\mathrm{SI}=0.11 \pm 0.02$ ) had a significantly greater contrast-dependent effect on extraclassical surround suppression (Fig. $4 D ; p=0.001$, Wilcoxon rank sum test).

We also observed differences between magnocellular and parvocellular neurons when comparing optimal stimulus size. With lower-contrast stimuli, magnocellular neurons preferred significantly larger stimuli than did parvocellular neurons (Fig. 4E; $p<0.001$, Wilcoxon rank sum test). Notably, this difference was not significant in response to higher-contrast stimuli (Fig. $4 E$; $p=0.13$, Wilcoxon rank sum test). Thus, cell-type differences in optimal stimulus size also depended on contrast.

Among the magnocellular neurons, optimal sizes were $~ 28 \%$ larger for lower-contrast stimuli compared with higher-contrast stimuli (Fig. $4 F$; mean optimal size: low contrast $=1.10^{\circ} \pm 0.06^{\circ}$; high contrast $=0.86^{\circ} \pm 0.05^{\circ}$, respectively; $p=0.006$, Wilcoxon rank sum test). This effect was typical for magnocellular neurons, with $91 \%$ of magnocellular neurons (32 of 35) showing an expansion in optimal stimulus size at lower contrasts compared with higher contrasts ( $p<0.001$, Wilcoxon signed-rank test). As with cell type-specific differences in extraclassical suppression, stimulus contrast did not have a significant effect on optimal stimulus size for the parvocellular neurons in our sample (Fig. $4 G$; mean optimal size: low contrast $=0.78^{\circ} \pm 0.06^{\circ}$; high contrast $=0.73^{\circ} \pm 0.06^{\circ} ; p=0.15$, Wilcoxon signed-rank test). Thus, compared with parvocellular neurons (mean change for optimal size $=0.05^{\circ} \pm 0.03^{\circ}$; bounded index $=0.03 \pm 0.02$; see Materials and Methods), magnocellular neurons (mean change for optimal size $=0.24^{\circ} \pm 0.03^{\circ}$; bounded index $=0.14 \pm 0.02$; see Materials and Methods) exhibited significantly greater contrastdependent changes in the spatial extent of the receptive field (Fig. $4 H ; p=0.001$, Wilcoxon rank sum test).

\section{ON-OFF asymmetries in spatial integration and contrast} gain control for cells in the magnocellular pathway

Together, these results show that magnocellular, but not parvocellular, neurons exhibit contrast-dependent changes in spatial integration, and spatial asymmetries between magnocellular and parvocellular neurons were contingent on contrast. In the sections below, we examine whether these effects of contrast further differentiate for the ON and OFF streams within the magnocellular pathway.

We first compared extraclassical suppression between our sample of ON-center and OFF-center magnocellular neurons 
A

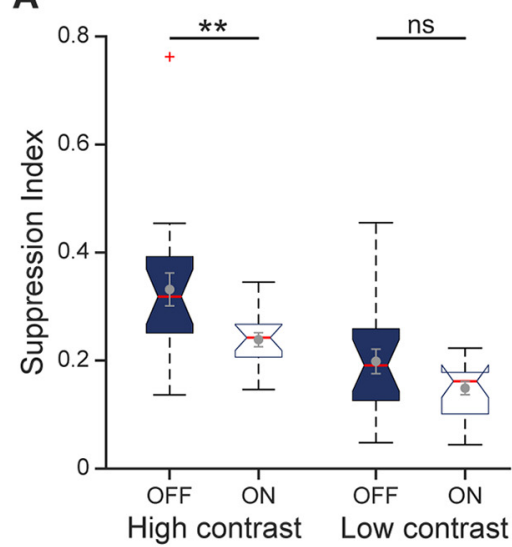

D

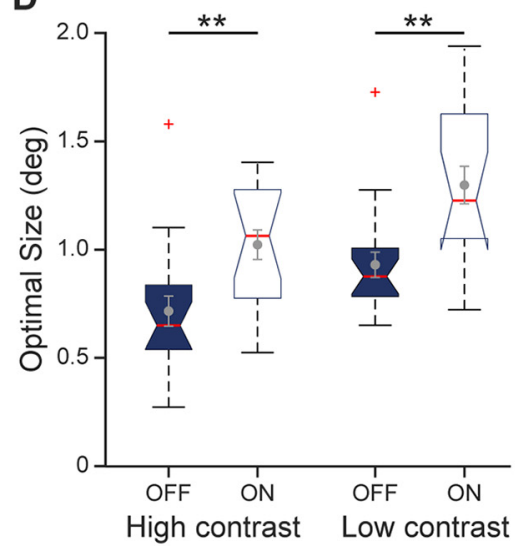

B

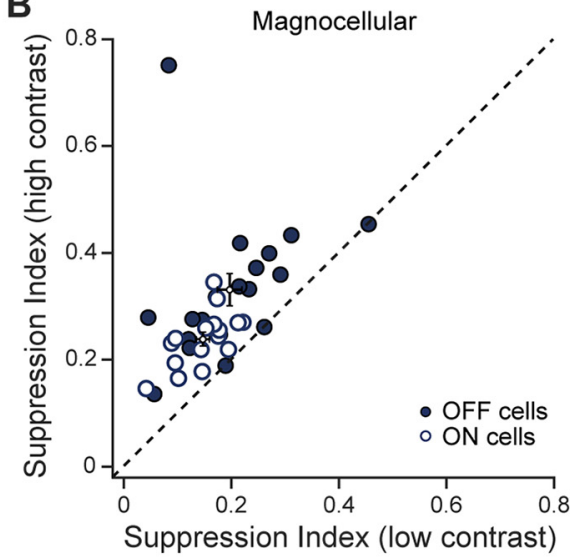

$E$

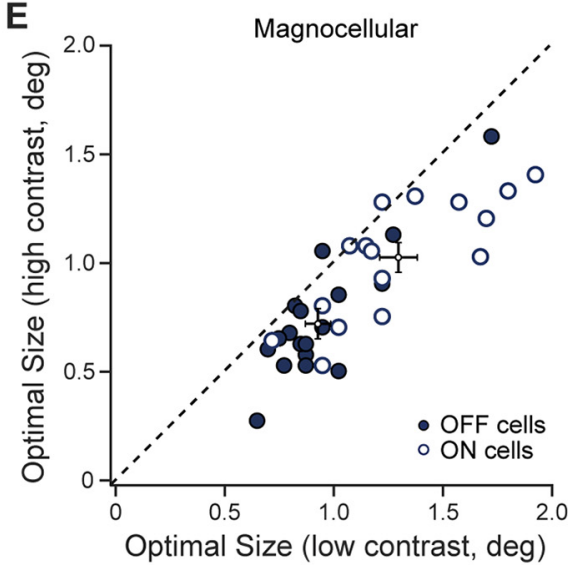

C

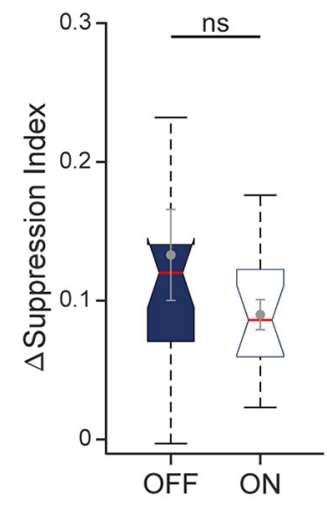

$F$

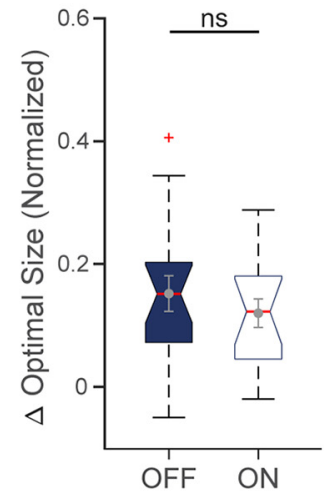

Figure 5. Asymmetries in suppression and size preference $0 \mathrm{~N}$ and $0 \mathrm{FF}$ cells in the magnocellular pathway. $A$, Box plots showing the distribution of suppression index values under high-contrast and low-contrast conditions for magnocellular OFF cells $(n=19)$ and ON cells $(n=16)$. Box plot conventions as described for Figure 4A. B, Scatter plot of the suppression index at highcontrast and low-contrast conditions for magnocellular OFF and ON cells. C, Distributions of contrast-dependent changes in the suppression index for magnocellular OFF cells and ON cells. $D$, Distributions of optimal size values under high-contrast and low-contrast conditions for magnocellular OFF cells $(n=19)$ and $0 \mathrm{~N}$ cells $(n=16)$. $\boldsymbol{E}$, Scatter plot of the optimal size at high-contrast and low-contrast conditions for magnocellular OFF cells and ON cells. $\boldsymbol{F}$, Distributions of contrast-dependent changes in optimal size (bounded index; see Materials and Methods) for magnocellular OFF cells and ON cells.

( $n=16$ and $n=19$, respectively). Comparisons revealed a significant difference for higher-contrast stimuli (Fig. $5 A$; mean SI: OFF cells $=0.33 \pm 0.03 ;$ ON cells $=0.24 \pm 0.01 ; p=0.006$ Wilcoxon rank sum test), although the difference did not quite reach significance for lower-contrast stimuli (mean SI: OFF cells $=0.20 \pm 0.02$; ON cells $=0.15 \pm 0.01 ; p=0.10$, Wilcoxon rank sum test). Nevertheless, for both the ON cells and the OFF cells, extraclassical suppression significantly increased in response to higher-contrast stimuli compared with lower-contrast stimuli (Fig. $5 B ; p<0.001$, Wilcoxon signed-rank test), and the contrastdependent changes in suppression indices between the two cell types were not significantly different (Fig. $5 C$; mean change SI: ON cells $=0.09 \pm 0.01 ;$ OFF cells $=0.13 \pm 0.03 ; p=0.23$, Wilcoxon rank sum test).

Previous studies have reported asymmetries in the size of receptive fields between $\mathrm{ON}$ and OFF cells in the macaque retina, with ON cells having larger receptive fields (Chichilnisky and Kalmar, 2002; but see Ravi et al., 2018). Thus, we next compared optimal stimulus size between our sample of ON-center and the OFF-center magnocellular neurons. We found that optimal sizes were larger for ON cells than OFF cells, regardless of contrast, as these differences were significant for both the higher contrast stimuli (Fig. $5 D$; mean optimal size: $\mathrm{ON}$ cells $=1.03^{\circ} \pm 0.07^{\circ}$; OFF cells $=0.72^{\circ} \pm 0.07^{\circ} ; p=0.003$, Wilcoxon rank sum test; mean effective contrast (i.e., $\%$ of maximal response) used for comparison: ON cells $=71.5 \pm 2.3 \%$; Off cells, $71.1 \pm 3.7 \%$; $p=0.68$, Wilcoxon rank sum test) and the lower contrast stimuli (Fig. $5 D$; mean optimal size: $\mathrm{ON}$ cells $=1.30^{\circ} \pm 0.09^{\circ}$; OFF cells $=0.93^{\circ} \pm 0.06^{\circ} ; p=0.001$, Wilcoxon rank sum test; mean contrast used for comparison $=$ ON cells, $8.4 \pm 1.2 \%$; OFF cells, $9.5 \pm 0.8 \% ; p=0.17$, Wilcoxon rank sum test). Furthermore, both $\mathrm{ON}$ and OFF cells exhibited significant increases in optimal stimulus size in response to lower contrast stimuli compared with higher contrast stimuli (Fig. $5 E ; p<0.001$, Wilcoxon signed-rank test), and the contrast-dependent changes were not significantly different for the two types of cells (Fig. $5 F ; p=0.56$, Wilcoxon rank sum test). Thus, these comparisons in extraclassical suppression strength and optimal stimulus size suggest that there are notable differences in spatial integration between $\mathrm{ON}$ and OFF magnocellular neurons.

Because receptive-field size is known to increase with eccentricity (Derrington and Lennie, 1984; Croner and Kaplan, 1995; Kremers and Weiss, 1997; Usrey and Reid, 2000; Solomon et al., 2002), we next tested whether these ON-OFF differences in optimal stimulus size observed in our sample of magnocellular neurons might be because of sampling differentially from cells at small and large eccentricities. As shown in Figure 6, optimal size indeed increased as a function of receptive-field eccentricity across magnocellular cells $(r=0.59, p<0.001)$, an effect evident for both the ON cells $(r=0.51, p=0.003)$ and the OFF cells 


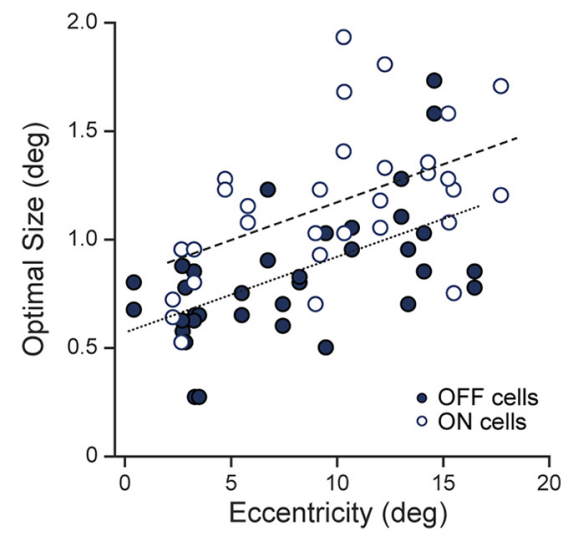

Figure 6. Optimal size as a function of eccentricity for OFF and ON cells in the magnocellular pathway.Scatter plot of the optimal size pooled across conditions of high-contrast and low-contrast against eccentricity, illustrating a significant positive correlation for both magnocellular OFF cells and ON cells.

$(r=0.49, p=0.002)$; however, the pool of ON cells did not differ significantly from the OFF cells in their eccentricity $(p=0.18$, Wilcoxon rank sum test). More importantly, at any given eccentricity optimal size was, on average, larger for ON cells compared with OFF cells. Similar to the results obtained in the retina (Chichilnisky and Kalmar, 2002), across our sample of LGN magnocellular neurons, $\mathrm{ON}$ cells preferred larger size stimuli than OFF cells.

We next asked how features of spatial integration are related to each other. To address this question, we compared suppression index values and optimal stimulus sizes across our sample of ON and OFF magnocellular neurons. As shown in Figure $7 A$, there was a negative correlation between these two values $(r=$ $-0.46, p<0.001$; ON cells: $r=-0.43, p=0.01$; OFF cells: $r=$ $-0.35, p=0.03)$. That is, cells that preferred smaller stimuli typically exhibited stronger extraclassical suppression compared with cells that preferred larger stimuli. To confirm the relationship between surround suppression (i.e., SI) and optimal size (RF), we computed an optimal size partial correlation while controlling for $\mathrm{C}_{50}\left(r_{\text {SIRF.C50 }}=-0.40, p<0.001\right)$. Together, these results suggest that $\mathrm{ON}$ cells integrate signals over larger regions of visual space compared with OFF cells.

Previous studies in the macaque retina have also noted ONOFF asymmetries in contrast response functions, with ON cells showing higher-contrast sensitivity (Chander and Chichilnisky, 2001; Chichilnisky and Kalmar, 2002). To test whether these asymmetries are also present in the macaque LGN, we compared contrast gain control between $\mathrm{ON}$ and OFF magnocellular neurons using the $\mathrm{C}_{50}$ as a measure for contrast gain control (the lower the $\mathrm{C}_{50}$, the greater the contrast gain control). As illustrated in Figure $7 B, C_{50}$ values were significantly lower for $\mathrm{ON}$ cells compared with OFF cells (mean $\mathrm{C}_{50}$ : ON cells $=10.6 \pm$ $1.1 \%$; OFF cells $=21.8 \pm 1.3 \% ; p<0.001$, Wilcoxon rank sum test), indicating $\mathrm{ON}$ magnocellular cells exhibit more pronounced contrast gain control compared with OFF magnocellular cells.

Given the differences in spatial integration and contrast gain control that we observed for magnocellular ON and OFF cells, we tested whether variations in the contrast-dependent strength of surround suppression correlated with the distribution of $\mathrm{C}_{50}$ values. As shown in Figure $7 C$, there was a positive correlation between these two values $(r=0.39, p<0.001)$, indicating an inverse relationship between these forms of gain control. That is, cells with higher suppression indices (stronger surround suppression) had higher $\mathrm{C}_{50}$ values (less contrast gain control). Thus, cells in the magnocellular pathway that exhibited stronger surround suppression exhibited less pronounced contrast gain control. Moreover, controlling for optimal stimulus size (RF) did not lower the strength of the relationship between extraclassical suppression (SI) and $\mathrm{C}_{50}$ by that much when we computed a partial correlation $\left(r_{\mathrm{SIC50.RF}}=0.35, p=0.003\right.$; see Materials and Methods), indicating that optimal stimulus size does not account for the inverse relationship. Together, these findings indicate manifestations of gain-control mechanisms that regulate neuronal responsiveness in the macaque LGN differentiate between the ON and OFF streams within the magnocellular pathway.

\section{Discussion}

Our results demonstrate spatial integration in LGN neurons is regulated in a contrast-dependent manner and differentiates across parallel visual pathways, having implications for downstream visual processing and perception (Nirenberg et al., 2010; Jiang et al., 2015). Most LGN neurons exhibited an increase in extraclassical suppression strength and a constriction in the optimal stimulus size in response to higher-contrast stimuli, indicating a reduction in spatial integration, as reported for V1 neurons (Levitt and Lund, 1997; Kapadia et al., 1999; Sceniak et al., 1999; Shushruth et al., 2009). Some neurons, notably those in the parvocellular pathway, did not exhibit these changes with contrast. Within the magnocellular pathway, ON and OFF neurons exhibited similar changes with contrast, despite ON neurons exhibiting broader spatial integration than OFF neurons. These findings demonstrate that the spatial dimensions of geniculate receptive fields are dynamic and support the notion that stimulus-evoked changes in the integration field are because of shifts in the balance between excitation and inhibition (Levitt and Lund, 1997; Kapadia et al., 1999; Cavanaugh et al., 2002), thus providing a way for the visual system to adjust the extent of spatial integration needed to accommodate for changes in the visual environment.

Previous studies reported extraclassical suppression in the retina is stronger for magnocellular-projecting RGCs compared with parvocellular-projecting RGCs (Solomon et al., 2006; Alitto and Usrey, 2008). Moreover, among magnocellular-projecting RGCs, contrast affects both surround suppression and optimal stimulus size (Solomon et al., 2006). Our results from LGN neurons therefore presumably include a retinal contribution; however, extraretinal mechanisms are also indicated, as extraclassical suppression and contrast gain control are augmented in the LGN (Rathbun et al., 2016; Fisher et al., 2017; but see Alitto and Usrey, 2008). Thus, mechanisms underlying the dynamic changes between excitation and inhibition likely rely on multiple circuits, including input from the retina, thalamic inhibition, and feedback from primary visual cortex (V1).

LGN relay cells integrate driving input that is stream specific from RGCs and modulatory inputs from a variety of feedforward and feedback sources. Feedback from V1 provides extensive modulatory input to the LGN that aligns with the feedforward parallel pathways (Briggs and Usrey, 2009). Synapses from corticogeniculate neurons are glutamatergic; however, their associated EPSPs are smaller compared with those from RGCs (Bloomfield and Sherman, 1988; Paulsen and Heggelund, 1994; Granseth and Lindström, 2003). The corticogeniculate feedback pathway also includes disynaptic inhibition onto relay cells, via local interneurons (Wilson, 1989) and neurons in the thalamic reticular nucleus (TRN; Bragg et al., 2017). Inactivation studies 

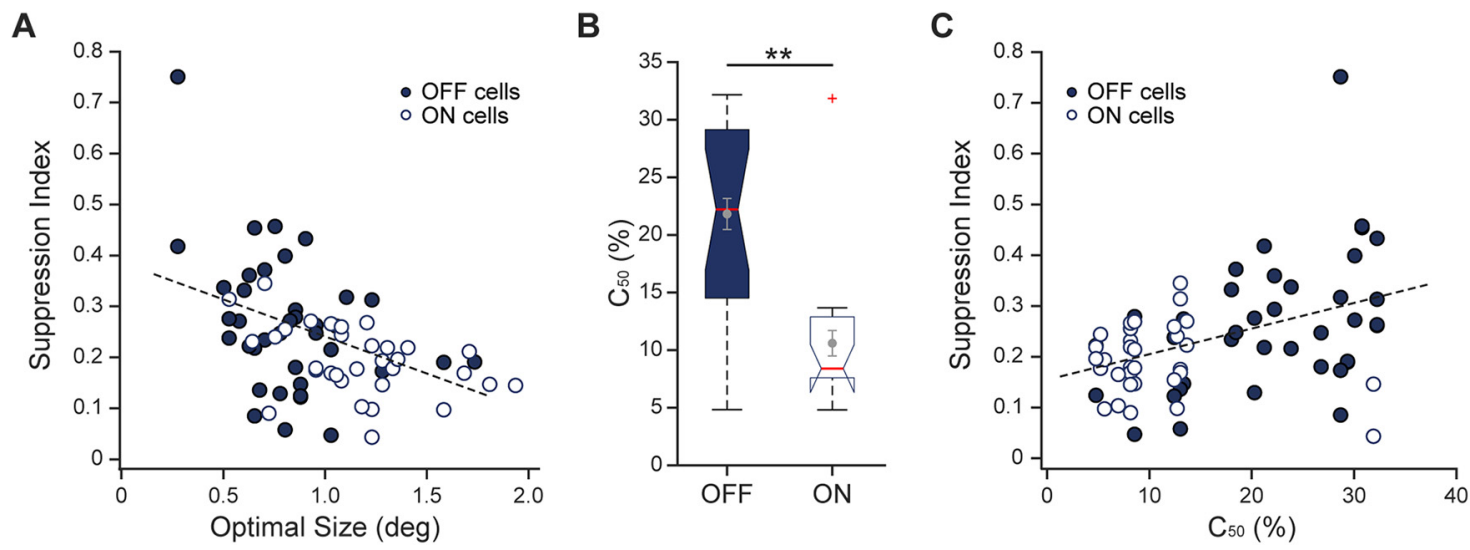

Figure 7. Functional asymmetries in forms of gain control across cells in the magnocellular pathway. A, Scatter plot of the suppression index against optimal size pooled across conditions of high and low contrast. $\boldsymbol{B}$, Distributions of the $C_{50}$ for magnocellular OFF cells $(n=19)$ and $0 \mathrm{~N}$ cells $(n=16)$. C, Scatter plot of the suppression index pooled across conditions of high and low contrast against the $C_{50}$.

indicate a role for corticogeniculate feedback in extraclassical suppression (Murphy and Sillito, 1987; Sillito and Jones, 2002; Andolina et al., 2013) and support the idea that feedback may contribute to contrast-dependent modulation of size tuning in the LGN (Sceniak et al., 2006). Importantly, local interneurons integrate retinal and corticogeniculate inputs, whereas TRN neurons integrate geniculocortical and corticogeniculate inputs, thereby providing the opportunity for gain modulation to occur in a feedforward and/or feedback manner (Vaingankar et al., 2012; Soto-Sánchez et al., 2017). The influence of extraretinal mechanisms also depends on where synapses are made on the dendrites of relay cells. RGCs and LGN interneurons preferentially target proximal dendrites (Wilson, 1989); corticogeniculate cells target distal dendrites (Wilson, 1989), and TRN neurons target both proximal and distal dendrites with a preference for more distal dendrites (Cucchiaro et al., 1991; Wang et al., 2001). Together, the different sources for inhibition and segregation of synaptic inputs onto different dendritic regions provide an opportunity for dynamic postsynaptic interactions. Although the details of these interactions remain undetermined, our results suggest they occur in a stream-specific fashion.

Our results demonstrate diversity in the spatial extent over which magnocellular and parvocellular neurons integrate visual signals. At high contrast, magnocellular neurons exhibited stronger extraclassical suppression and comparable optimal stimulus sizes with parvocellular neurons, whereas at low contrast, magnocellular neurons preferred larger stimulus sizes and comparable extraclassical suppression with parvocellular neurons. Under lower contrasts, our results support the generally accepted view that magnocellular neurons have larger receptive fields than parvocellular neurons. Interestingly, some past studies using highcontrast stimuli reported no differences between magnocellular and parvocellular neurons in receptive-field size (Levitt et al., 2001), which is consistent with our results under higher contrasts. Together, results from this study demonstrate that magnocellular neurons integrate over a larger visual field than parvocellular neurons at lower contrasts, but not at higher contrasts.

To facilitate comparisons between magnocellular and parvocellular neurons, we selected contrast levels within the linear portion of the contrast-response function of the cell. Our goal was to use contrast levels that would generate relatively similar responses (with respect to the maximum response of each cell) across cells; however, the effective contrasts selected (i.e., the percentage of maximum response) for the low-contrast condition were higher for the magnocellular neurons. With this incongruity noted, it seems unlikely that the difference in effective contrasts would account for the contrast-dependent spatial asymmetries we observed between magnocellular and parvocellular neurons, because magnocellular neurons exhibited a larger, not smaller, dynamic range in spatial integration than parvocellular neurons.

Comparisons between magnocellular ON and OFF neurons uncovered differences in surround suppression and receptivefield size indicating that $\mathrm{ON}$ neurons integrate over a larger visual field than OFF neurons regardless of contrast. The ON and OFF pathways are established in the retina and separately convey increments and decrements in light intensity to cortex (Werblin and Dowling, 1969; Schiller et al., 1986; Schiller, 1992). The ON and OFF pathways extend the dynamic range of operation and are generally considered symmetric systems that are opposite in sign. Nevertheless, ON-OFF asymmetries in dendritic-field size (Peichl et al., 1987; Peichl, 1989; Tauchi et al., 1992; Manookin et al., 2008; Ratliff et al., 2010), receptive-field size (Chichilnisky and Kalmar, 2002; Ravi et al., 2018), contrast sensitivity (Chander and Chichilnisky, 2001; Chichilnisky and Kalmar, 2002; Zaghloul et al., 2003), spatial integration (Turner and Rieke, 2016; Ravi et al., 2018), and temporal integration (Chichilnisky and Kalmar, 2002; Pandarinath et al., 2010; Ravi et al., 2018) have been reported in the retina for a range of species, suggesting that these functional differences are optimized for encoding sensory information efficiently (Gjorgjieva et al., 2014). The ON-OFF asymmetries in spatial integration reported here for LGN neurons may also influence the capacity for encoding global and local features in a visual scene, as reported for $\mathrm{V} 1$ responses to lights and darks (Mazade et al., 2019).

Diversity in the expression of gain control across $\mathrm{ON}$ and OFF magnocellular neurons may also be optimal for encoding and integrating a range of visual signals efficiently (Zaghloul et al., 2003; Nirenberg et al., 2010). Contrast gain control amplifies response gain at low contrast, optimizing signal-to-noise ratio and reducing the loss of weak signals; at high contrast, response gain is compressed and integration time is shortened, protecting against saturation (Shapley and Victor, 1978, 1981; Victor, 1987). Thus, neurons expressing more pronounced contrast gain control should exhibit shorter integration times. Moreover, given that previous studies have reported an inverse relationship between temporal integration and spatial integration (Frishman et al., 1987; Lee, 1996; Troy and Shou, 2002; Alitto and Usrey, 2015)—a shorter 
integration time implies larger spatial integration (Ravi et al., 2018) -neurons exhibiting more pronounced contrast gain control should also exhibit larger spatial integration. This prediction is consistent with the differences reported here for magnocellular neurons; $\mathrm{ON}$ neurons exhibited larger spatial integration and more pronounced contrast gain control than OFF neurons. Together, these results suggest that differences in the expression of gain control across parallel visual pathways in the macaque LGN reflect how the visual system exploits functional asymmetries, thereby extending the dynamic range of operation to compensate for limitations in signaling capacity and to optimize visual encoding (Nirenberg et al., 2010).

Gain-control mechanisms operate at every stage in the visual system and adjust how visual neurons respond to different stimulus conditions in the natural environment. Similar to how the pupil constricts in response to light and dilates in response to dark, the spatial extent of the receptive field is dynamic, exhibiting constriction and expansion in response to changes in stimulus contrast. These dynamic changes likely optimize the capacity to integrate a range of visual signals and have perceptual consequences. At lower contrasts, expansion of the receptive field and less pronounced surround suppression enhance sensitivity as signals are integrated over larger regions of visual space, thus providing a substrate for improved stimulus detection. Whereas at higher contrasts, constriction of the receptive field and more pronounced surround suppression sharpens spatial boundaries, thus providing a substrate for improved stimulus discrimination. Together, these findings suggest that diversity across the parallel visual pathways provides a functional benefit for downstream visual processing and perception by optimizing the transmission of information about a visual scene in an efficient manner.

\section{References}

Albrecht DG, Hamilton DB (1982) Striate cortex of monkey and cat: contrast response function. J Neurophysiol 48:217-237.

Alitto HJ, Usrey WM (2008) Origin and dynamics of extraclassical suppression in the lateral geniculate nucleus of the macaque monkey. Neuron 57:135-146

Alitto HJ, Usrey WM (2015) Surround suppression and temporal processing of visual signals. J Neurophysiol 113:2605-2617.

Alitto HJ, Moore BD, Rathbun DL, Usrey WM (2011) A comparison of visual responses in the lateral geniculate nucleus of alert and anaesthetized macaque monkeys. J Physiol 589:87-99.

Allman J, Miezin F, McGuinness E (1985) Stimulus specific responses from beyond the classical receptive field: neurophysiological mechanisms for local-global comparisons in visual neurons. Annu Rev Neurosci 8:407430.

Andolina IM, Jones HE, Sillito AM (2013) Effects of cortical feedback on the spatial properties of relay cells in the lateral geniculate nucleus. J Neurophysiol 109:889-899.

Benardete EA, Kaplan E, Knight BW (1992) Contrast gain control in the primate retina: p cells are not X-like, some M cells are. Vis Neurosci 8:483486.

Bishop PO, Evans WA (1956) The refractory period of the sensory synapses of the lateral geniculate nucleus. J Physiol 134:538-557.

Bloomfield SA, Sherman SM (1988) Postsynaptic potentials recorded in neurons of the cat's lateral geniculate nucleus following electrical stimulation of the optic chiasm. J Neurophysiol 60:1924-1945.

Bonin V, Mante V, Carandini M (2005) The suppressive field of neurons in lateral geniculate nucleus. J Neurosci 25:10844-10856.

Bragg EM, Fairless EA, Liu S, Briggs F (2017) Morphology of visual sector thalamic reticular neurons in the macaque monkey suggests retinotopically specialized, parallel stream-mixed input to the lateral geniculate nucleus. J Comp Neurol 525:1273-1290.

Briggs F, Usrey WM (2009) Parallel processing in the corticogeniculate pathway of the macaque monkey. Neuron 62:135-146.
Cavanaugh JR, Bair W, Movshon JA (2002) Nature and interaction of signals from the receptive field center and surround in macaque v1 neurons. J Neurophysiol 88:2530-2546.

Chander D, Chichilnisky EJ (2001) Adaptation to temporal contrast in primate and salamander retina. J Neurosci 21:9904-9916.

Chichilnisky EJ, Kalmar RS (2002) Functional asymmetries in ON and OFF ganglion cells of primate retina. J Neurosci 22:2737-2747.

Croner LJ, Kaplan E (1995) Receptive fields of P and M ganglion cells across the primate retina. Vision Res 35:7-24.

Cucchiaro JB, Uhlrich DJ, Sherman SM (1991) Electron-microscopic analysis of synaptic input from the perigeniculate nucleus to the A-laminae of the lateral geniculate nucleus in cats. J Comp Neurol 310:316-336.

DeAngelis GC, Freeman RD, Ohzawa I (1994) Length and width tuning of neurons in the cat's primary visual cortex. J Neurophysiol 71:347-374.

Derrington AM, Lennie P (1984) Spatial and temporal contrast sensitivities of neurones in lateral geniculate nucleus of macaque. J Physiol 357:219240.

Enroth-Cugell C, Freeman AW (1987) The receptive-field spatial structure of cat retinal Y cells. J Physiol 384:49-79.

Enroth-Cugell C, Robson JG (1966) The contrast sensitivity of retinal ganglion cells of the cat. J Physiol 187:517-552.

Fisher TG, Alitto HJ, Usrey WM (2017) Retinal and nonretinal contributions to extraclassical surround suppression in the lateral geniculate nucleus. J Neurosci 37:226-235.

Frishman L, Freeman A, Troy J, Schweitzer-Tong D, Enroth-Cugell C (1987) Spatiotemporal frequency responses of cat retinal ganglion cells. J Gen Physiol 89:599-628.

Gjorgjieva J, Sompolinsky H, Meister M (2014) Benefits of pathway splitting in sensory coding. J Neurosci 34:12127-12144.

Granseth B, Lindström S (2003) Unitary EPSCs of corticogeniculate fibers in the rat dorsal lateral geniculate nucleus in vitro. J Neurophysiol 89:29522960.

Greschner M, Heitman AK, Field GD, Li PH, Ahn D, Sher A, Litke AM, Chichilnisky EJ (2016) Identification of a retinal circuit for recurrent suppression using indirect electrical imaging. Curr Biol 26:1935-1942.

Jarsky T, Cembrowski M, Logan SM, Kath WL, Riecke H, Demb JB, Singer JH (2011) A synaptic mechanism for retinal adaptation to luminance and contrast. J Neurosci 31:11003-11015.

Jiang Y, Purushothaman G, Casagrande VA (2015) The functional asymmetry of ON and OFF channels in the perception of contrast. J Neurophysiol 114:2816-2829.

Jones HE, Andolina IM, Oakely NM, Murphy PC, Sillito AM (2000) Spatial summation in lateral geniculate nucleus and visual cortex. Exp Brain Res 135:279-284.

Kapadia MK, Westheimer G, Gilbert CD (1999) Dynamics of spatial summation in primary visual cortex of alert monkeys. Proc Natl Acad Sci U S A 96:12073-12078.

Kim KJ, Rieke F (2001) Temporal contrast adaptation in the input and output signals of salamander retinal ganglion cells. J Neurosci 21:287-299.

Kremers J, Weiss S (1997) Receptive field dimensions of lateral geniculate cells in the common marmoset (Callithrix jacchus). Vision Res 37:21712181.

Lee BB (1996) Receptive field structure in the primate retina. Vision Res 36:631-644

Levitt JB, Lund JS (1997) Contrast dependence of contextual effects in primate visual cortex. Nature 387:73-76.

Levitt JB, Schumer RA, Sherman SM, Spear PD, Movshon JA (2001) Visual response properties of neurons in the LGN of normally reared and visually deprived Macaque monkeys. J Neurophysiol 85:2111-2129.

Manookin MB, Beaudoin DL, Ernst ZR, Flagel LJ, Demb JB (2008) Disinhibition combines with excitation to extend the operating range of the OFF visual pathway in daylight. J Neurosci 28:4136-4150.

Mazade R, Jin J, Pons C, Alonso J-M (2019) Functional specialization of ON and OFF cortical pathways for global-slow and local-fast vision. Cell Rep 27:2881-2894.e5.

Merigan WH, Maunsell JHR (1993) How parallel are the primate visual pathways?Annu Rev Neurosci 16:369-402.

Murphy PC, Sillito AM (1987) Corticofugal feedback influences the generation of length tuning in the visual pathway. Nature 329:727-729.

Naka KI, Rushton WAH (1966) S-potentials from luminosity units in the retina of fish (Cyprinidae). J Physiol 185:587-599. 
Nirenberg S, Bomash I, Pillow JW, Victor JD (2010) Heterogeneous response dynamics in retinal ganglion cells: the interplay of predictive coding and adaptation. J Neurophysiol 103:3184-3194.

Pandarinath C, Victor JD, Nirenberg S (2010) Symmetry breakdown in the ON and OFF pathways of the retina at night: functional implications. J Neurosci 30:10006-10014.

Paulsen O, Heggelund P (1994) The quantal size at retinogeniculate synapses determined from spontaneous and evoked EPSCs in guinea-pig thalamic slices. J Physiol 480:505-511.

Peichl L (1989) Alpha and delta ganglion cells in the rat retina. J Comp Neurol 286:120-139.

Peichl L, Ott H, Boycott BB (1987) Alpha ganglion cells in mammalian retinae. Proc R Soc Lond B Biol Sci 231:169-197.

Rathbun DL, Alitto HJ, Warland DK, Usrey WM (2016) Stimulus contrast and retinogeniculate signal processing. Front Neural Circuits 10:1-10.

Ratliff CP, Borghuis BG, Kao Y-H, Sterling P, Balasubramanian V (2010) Retina is structured to process an excess of darkness in natural scenes. Proc Natl Acad Sci U S A 107:17368-17373.

Ravi S, Ahn D, Greschner M, Chichilnisky EJ, Field GD (2018) Pathway-specific asymmetries between $\mathrm{ON}$ and OFF visual signals. J Neurosci 38:9728-9740.

Rieke F (2001) Temporal contrast adaptation in salamander bipolar cells. J Neurosci 21:9445-9454

Sceniak MP, Ringach DL, Hawken MJ, Shapley R (1999) Contrast's effect on spatial summation by macaque V1 neurons. Nat Neurosci 2:733-739.

Sceniak MP, Chatterjee S, Callaway EM (2006) Visual spatial summation in macaque geniculocortical afferents. J Neurophysiol 96:3474-3484.

Schiller PH (1992) The ON and OFF channels of the visual system. Trends Neurosci 15:86-92.

Schiller PH, Logothetis NK (1990) The color-opponent and broad-band channels of the primate visual system. Trends Neurosci 13:392-398.

Schiller PH, Sandell JH, Maunsell JHR (1986) Functions of the ON and OFF channels of the visual system. Nature 322:824-825.

Shapley RM, Victor JD (1978) The effect of contrast on the transfer properties of cat retinal ganglion cells. J Physiol 285:275-298.

Shapley RM, Victor JD (1981) How the contrast gain control modifies the frequency responses of cat retinal ganglion cells. J Physiol 318:161-179.

Shushruth S, Ichida JM, Levitt JB, Angelucci A (2009) Comparison of spatial summation properties of neurons in macaque V1 and V2. J Neurophysiol 102:2069-2083.

Sillito AM, Jones HE (2002) Corticothalamic interactions in the transfer of visual information. Philos Trans R Soc Lond B Biol Sci 357:1739-1752.

Sillito AM, Cudeiro J, Murphy PC (1993) Orientation sensitive elements in the corticofugal influence on centre-surround interactions in the dorsal lateral geniculate nucleus. Exp Brain Res 93:6-16.
Solomon SG, White AJR, Martin PR (2002) Extraclassical receptive field properties of parvocellular, magnocellular, and koniocellular cells in the primate lateral geniculate nucleus. J Neurosci 22:338-349.

Solomon SG, Lee BB, Sun H (2006) Suppressive surrounds and contrast gain in magnocellular-pathway retinal ganglion cells of macaque. J Neurosci 26:8715-8726.

Soto-Sánchez C, Wang X, Vaingankar V, Sommer FT, Hirsch JA (2017) Spatial scale of receptive fields in the visual sector of the cat thalamic reticular nucleus. Nat Commun 8:800.

Tauchi M, Morigiwa K, Fukuda Y (1992) Morphological comparisons between outer and inner ramifying alpha cells of the albino rat retina. Exp Brain Res 88:67-77.

Troy JB, Shou T (2002) The receptive fields of cat retinal ganglion cells in physiological and pathological states: where we are after half a century of research. Prog Retin Eye Res 21:263-302.

Turner MH, Rieke F (2016) Synaptic rectification controls nonlinear spatial integration of natural visual inputs. Neuron 90:1257-1271.

Usrey WM, Alitto HJ (2015) Visual functions of the thalamus. Annu Rev Vis Sci 1:351-371.

Usrey WM, Reid RC (2000) Visual physiology of the lateral geniculate nucleus in two species of New World monkey: Saimiri sciureus and Aotus trivirgatis. J Physiol 523:755-769.

Vaiceliunaite A, Erisken S, Franzen F, Katzner S, Busse L (2013) Spatial integration in mouse primary visual cortex. J Neurophysiol 110:964-972.

Vaingankar V, Soto-Sanchez C, Wang X, Sommer FT, Hirsch JA (2012) Neurons in the thalamic reticular nucleus are selective for diverse and complex visual features. Front Integr Neurosci 6:1-17.

Victor JD (1987) The dynamics of the cat retinal X cell centre. J Physiol 386:219-246.

Wang S, Bickford ME, Van Horn SC, Erisir A, Godwin DW, Sherman SM (2001) Synaptic targets of thalamic reticular nucleus terminals in the visual thalamus of the cat. J Comp Neurol 440:321-341.

Weick M, Demb JB (2011) Delayed-rectifier K channels contribute to contrast adaptation in mammalian retinal ganglion cells. Neuron 71:166179.

Werblin FS, Dowling JE (1969) Organization of the retina of the mudpuppy, Necturus maculosus. II. Intracellular recording. J Neurophysiol 32:339355.

Wilson JR (1989) Synaptic organization of individual neurons in the macaque lateral geniculate nucleus. J Neurosci 9:2931-2953.

Zaghloul KA, Boahen K, Demb JB (2003) Different circuits for ON and OFF retinal ganglion cells cause different contrast sensitivities. J Neurosci 23:26452654.

Zaghloul KA, Manookin MB, Borghuis BG, Boahen K, Demb JB (2007) Functional circuitry for peripheral suppression in mammalian Y-type retinal ganglion cells. J Neurophysiol 97:4327-4340. 